\title{
PENGARUH ORIENTASI KEWIRAUSAHAAN DAN ORIENTASI PEMBELAJARAN TERHADAP KINERJA PEMASARAN MELALUI O RIENTASI PELANGGAN DAN ORIENTASI INOVASI UKM KONVEKSI DI KABUPATEN SRAGEN
}

\author{
Aris Tri Haryanto \\ Septiana Novita Dewi \\ Adnan Terry Suseno \\ Sekolah Tinggi Ilmu Ekonomi Adi Unggul Bhirawa Surakarta \\ arisharyanto26@yahoo.co.id
}

\begin{abstract}
ABSTRAK
The purpose of this study is to determine the effect of entrepreneurship orientation and learning orientation on marketing performance through customer orientation and innovation orientation of conventional SME in Sragen regency. The population of this research is convection SME in Sragen regency. The sample is 100 respondents. The analysis used is path analysis. The result of this research shows that entrepreneurship orientation and learning orientation have positive and significant impact on customer orientation. The orientation of entrepreneurship and learning orientation has a positive and significant impact on innovation orientation. The orientation of entrepreneurship, customer orientation and innovation orientation have a positive and significant impact on marketing performance. And the learning orientation has a negative and insignificant effect on marketing performance. The most dominant variable is the variable orientation of learning through innovation orientation to marketing performance.
\end{abstract}

Keywords: Orientation of Entrepreneurship, Learning Orientation, Customer Orientation, Innovation Orientation, Marketing Performance

\section{PENDAHULUAN}

Konstribusi UKM pada perekonomian yang sangat besar dan perkembangan yang semakin meningkat dari segi kuantitas ternyata belum diimbangi dengan peningkatan kualitas. Kualitas UKM yang belum meningkat yaitu kualitas dilihat dari managerialnya. Kualitas managerial ini terdiri dari kualitas kewirausahaan, keuangan, sumber daya manusia, pemasaran, orientasi inovasi dan kemampuan perubahan organisasi (Altindag, Zehir \& Acar, 2011). Konstribusi UKM dalam perekonomian antara lain: mampu menciptakan lapangan kerja karena padat karya, meningkatkan pertumbuhan ekonomi regional, bertindak sebagai mitra yang saling melengkapi untuk perusahaan besar, sebagai pelatihan bagi pengusaha dan pekerja muda dalam mengembangkan bisnis dan ketrampilan interpersonal. UKM mampu mengurangi kerentanan negara terhadap krisis keuangan dengan keberhasilan dan kelangsungan hidupnya (Beal \& Abdullah, 2003).

Kewirausahaan merupakan proses strategi pembuatan kebijakan yang memungkinkan pengusaha untuk bertindak dan menjalankan 
organisasi sesuai dengan yang direncanakan dan mengacu pada hal-hal yang baru(Wiklund, 2009). Keuangan merupakan cara mengelola usaha terutama tentang penggunaan dan perolehan dana usaha. Kualitas UKM yang belum berkembang dilihat dari keuangan ini misalnya cara penggajian yang belum menggunakan system yang baik. Salah satu cara yang dapat digunakan adalah sistem reward berbasis pemasaran artinya jika kinerjanya semakin baik maka semakin besar reward yang diberikan (Stare, 2012). Kualitas UKM dilihat dari pengembangan sumber daya manusia masih perlu ditingkatkan. Sebagian besar pengelola UKM belum berpendidikan tinggi sehingga perlu pembelajaran. Pembelajaran merupakan faktor penting dalam memperoleh keunggulan kompetitif (Morgan, R.E, \& Berthon, P, 2008). Kualitas UKM dilihat dari pemasaran terutama dilihat perilakuan mereka terhadap pelanggan dan pesaing. Hal ini ini sering disebut dengan orientasi pasar.

Kualitas UKM dilihat dari pengembangan proses produksi dan produk yang dihasilkan merupakan hal yang penting. Hal ini sering disebut dengan istilah oientasi inovasi. Orientasi inovasi merupakan pengembangan produk saat ini dan proses produksi, serta inovasi radikal yang pada dasarnya pengembangan atau penerapan ide-ide baru dan teknologi baru (Dewar dan Dutton, 1986). Kualitas UKM yang perlu ditingkatkan yaitu kemampuan untuk berubah dalam menghadapi dunia bisnis yang selalu berubah. Kemampuan perubahan oganisasi merupakan perubahan secara terus menerus, mengantisipasi dan menyesuaikan pemikiran dan tindakan yang dilakukan oleh anggota organisasi untuk mencapai masa depan yang diinginkan (Buono \& Kerber, 2008). Peningkatan kualitas UKM dengan berbagai strategi pemasaran ini sering disebut dengan penerapkan orientasi strategi (Urata, 2000; Altindag, et al.,2010). Nadrol, Breen dan Josiassen (2010) di samping orientasi strategi terdiri atas orientasi pasar dan orientasi kewirausahaan ditambahkan orientasi interaktif. Sementara itu, yang digunakan Altindag et al. (2010) yaitu orientasi pelanggan, orientasi kewirausahaan, orientasi pembelajaran dan orientasi inovasi. Dimensi orientasi strategi yang paling sering dibicarakan oleh peneliti maupun ahli pemasaran adalah orientasi pasar. Orientasi pasar dapat dibedakan menjadi orientasi pelanggan dan pesaing. Perusahaan yang ingin menerapkan orientasi pelanggan harus melaksanakan 5 kegiatan yaitu: 1) Menentukan kebutuhan pokok pembeli 2) Memilih kelompok pembeli 3) Menentukan produk dan program pemasaran 4) Mengadakan penelitian konsumen 5) Menentukan dan melaksanakan strategi pilihan yang baik (Kotler, 2010). Orientasi pasar dapat dilaksanakan dengan baik di tingkat mikro maupun makro (Silkoset, 2009). Sementara itu Andrew (2010), menyatakan pemerintah Kanada telah melaksanakan kebijakan yang berorientasi pasar baik di tingkat makro dan mikro. Kebijakan penerapan orientasi pasar pada tingkat makro akan mendorong pertumbuhan produktivitas. Sejak tahun 2000 pertumbuhan produktivitas di Kanada telah suram, jauh di bawah Amerika Serikat dan perkiraan ataupun sejarah negara Kanada. Setelah kebijakan publik yang berorientasi pasar dijalankan maka produktifitas di Kanada mengalami peningkatan. Kebijakan penerapan orientasi pasar ditingkat mikro dapat meningkatkan kemampuan perusahaan dalam mencapai tujuannya.

Dalam melaksanakan orientasi pasar manajemen dapat mengadopsi satu dari lima konsep pemasaran (Kotler, 2010). Lima konsep pemasaran itu adalah:

1. Konsep produksi yang menyatakan bahwa tugas manajemen adalah meningkatkan efisiensi produksi dan menurunkan harga. Konsep ini mempunyai anggapan bahwa konsumen akan menyukai produk yang harganya rendah. 
2. Konsep produk yang menyatakan bahwa tugas manajemen adalah menyediakan produk yang berkualitas tinggi. Konsep ini mempunyai anggapan bahwa konsumen menyukai produk yang menawarkan kualitas, kinerja, dan fitur inovatif yang terbaik karena itu hanya diperlukan sedikit usaha promosi.

3. Konsep penjualan yang menyatakan bahwa konsumen tidak akan membeli produk organisasi kecuali organisasi mengadakan penjualan dalam skala besar dan usaha promosi. Konsep ini mempunyai anggapan bahwa konsumen menyukai produk yang di promosikan secara terus-menerus.

4. Konsep pemasaran yang menyatakan bahwa pencapaian tujuan organisasi tergantung pada penentuan kebutuhan dan keinginan target pasar dan menghantarkan kepuasan yang diinginkan secara lebih efektif dan efisien dari pada pesaing.

5. Konsep pemasaran berwawasan sosial. Konsep pemasaran berwawasan sosial ini menyatakan bahwa menghasilkan kepuasan pelanggan dan kesejahteraan sosial jangka panjang adalah kunci untuk mencapai tujuan perusahaan dan memenuhi tanggungjawabnya (Kotler, 2010).

Orientasi pelanggan berpengaruh positif dan signifikan pada orientasi inovasi. Orientasi pelanggan memiliki hubungan positif dan signifikan pada inovasi inkremental dan berpengaruh positif dan signifikan pada inovasi radikal (Grawe, 2009; Lewrick 1, Omar2 \& Robert, 2011). Demikian juga Kaya dan Patton (2011) hasil penelitiannya menyatakan bahwa pengetahuan berbasis sumber daya, orientasi belajar, dan orientasi pasar berpengaruh positif signifikan pada kinerja inovasi. Pada Tabel 1 disajikan Maping hasil penelitian pengaruh orientasi pelanggan pada orientasi inovasi.

\section{Tabel 1. Maping Hasil Penelitian Pengaruh Orientasi Pelanggan pada Orientasi Inovasi,}

\begin{tabular}{|l|l|l|l|}
\hline \multicolumn{1}{|c|}{ Peneliti } & Tahun & Analisis & \multicolumn{1}{c|}{ Hasil } \\
\hline Lukas \& Ferrell & 2000 & Regresi & Pengaruh negatif \\
Verhess \&Meulenberg & 2004 & Regresi & Pengaruhnya negatif \\
Grawe & 2009 & Regresi & Berpengaruh positif \\
Lewrick, et al & 2011 & SEM & Berpengaruh positif \\
Kaya \& Patton & 2011 & SEM & Berpengaruh positif \\
\hline
\end{tabular}

Sumber : Lukas \& Ferrell, 2000; Verhess \& Meulenberg, 2004; Grawe dan peneliti lainnya.

Berdasarkan uraian tersebut dan hasil penelitian yang disajikan dalam Tabel 1, memberi informasi bahwa terjadi research gap hasil penelitian pengaruh orientasi pesaing pada orientasi inovasi. Research gapnya yaitu pengaruh orientasi pasar pada orientasi inovasi belum konsisten, ada yang menunjukkan berpengaruh positif dan negatif. Kemudian, penelitian tentang pengaruh orientasi inovasi dan kinerja pemasaran juga menghasilkan temuan yang bervariasi. Mavondo, Felix, Chimhanzi, Jacqueline, Stewart dan Jillian (2005) menghasilkan temuan bahwa orientasi inovasi tidak memiliki pengaruh yang positif signifikan pada efektifitas pemasaran. Darroch (2005), hasil penelitiannya menyatakan orientasi inovasi tidak memiliki pengaruh pada kinerja baik yang diukur dengan kinerja keuangan maupun kinerja non keuangan yaitu market share dan pertumbuhan penjualan.

Perusahaan yang tidak menggunakan teknologi tinggi harus proaktif pada peluag pasar, menerima dan memimpin inovasi. Ilmu pengetahuan dan teknologi merupakan sumber pembangunan ekonomi yang sangat penting. Iptek berpengaruh pada restrukturisasi dan produktivitas (Sylvie, 2008; Beatrix, 2008). Kemudian Jhonson, Dibrell dan Eric (2009), hasil penelitiannya menyatakan orientasi inovasi 
yang terintegrasi berpengaruh positif pada kinerja perusahaan industri manufaktur. Inovasi terintergrasi meliputi inovasi organisasi, inovasi produk, inovasi proses dan inovasi pemasaran. Perusahaan lebih sukses jika lebih berfokus pada kegiatan inovasi. Demikian juga Gurhan, Gunduz, Kemal dan Lutfihak (2011) menyatakan bahwa restrukturisasi dan produktivitas berpengaruh positif signifikan pada keunggulan kompetitif. Keunggulan kompetitif menentukan kinerja. Pada Tabel 2 disajikan maping hasil penelitian pengaruh orientasi inovasi pada kinerja pemasaran.

\section{Tabel 2}

Maping Hasil Penelitian Pengaruh Orientasi Inovasi pada Kinerja Pemasaran

\begin{tabular}{|l|c|l|l|}
\hline \multicolumn{1}{|c|}{ Peneliti } & Tahun & \multicolumn{1}{|c|}{ Analisis } & \multicolumn{1}{c|}{ Hasil } \\
\hline Mavondo et al., & 2005 & Regresi & Berpengaruh negatif \\
Darroch & 2005 & Regresi & Berpengaruh negatif \\
Sylvie & 2008 & Regresi & Berpengaruh positif signifikan \\
Beatrix & 2008 & SEM & Berpengaruh positif signifikan \\
Jhonson et al. & 2009 & SEM & Berpengaruh positif signifikan \\
Gurham et al. & 2011 & Regresi & Berpengaruh positif signifikan \\
\hline
\end{tabular}

Sumber: Mavondo et al., 2005; Darroch, 2005; Silvie, 2009 dan peneliti lainnya

Berdasarkan uraian tersebut dan hasil penelitian yang disajikan dalam Tabel I.2, diperoleh informasi bahwa terjadi research gap pengaruh orientasi inovasi pada kinerja pemasaran. Research gapnya yaitu pengaruh orientasi inovasi pada kinerja pemasaran bervariasi. ada yang menunjukkan berpengaruh negatif dan ada yang berpengaruh positif signifikan. Orientasi kewirausahaan diyakini memiliki hubungan langsung dengan orientasi pelanggan. Orientasi kewirausahaan yang berkelanjutan mempengaruhi niat berwirausaha. Perilaku kewirausahaan berpengaruh positif pada orientasi pelanggan. Perusahaan dan sumber daya lokal mempengaruhi pada kinerja internasional (Matsuno \& Metzer, 2000; Andreas dan Marcus, 2010; Basile, 2012). Sementara itu Cristina (2011) hasil penelitiannya menunjukkan bahwa orientasi kewirausahaan dan perilaku wirausaha mempengaruhi orientasi pelanggan dan kinerja pemasaran yang beroperasi dalam lingkungan yang dinamis.

Perusahaan yang memiliki tingkat orientasi belajar yang tinggi cenderung memiliki kinerja yang lebih tinggi dibanding dengan pesaingnya, terutama dalam lingkungan yang tidak pasti dan intensitas persaingan yang tinggi. Orientasi pembelajaran memungkinkan perusahaan untuk memiliki target pasar dan memasuki pasar baru (Mavondo et al., 2005). Orientasi belajar memiliki pengaruh langsung pada orientasi pelanggan dan orientasi belajar tidak memiliki dampak langsung dan signifikan pada kinerja perusahaan (Wencong, Guilong \& Yu, 2011).

Peneliti sebelumnya orientasi pelanggan dan pesaing digabugkan sehingga tidak dapat diketahui yang mempengaruhi oientasi inovasi itu orientasi pelanggan atau pesaing atau keduanya. Misalnya, Grawe (2009); Sergio dan Roberto (2008) menyatakan orientasi pasar berpengaruh positif dan signifikan pada orientasi inovasi. Melihat hasil ini maka peneliti merinci orientasi pasar menjadi orientasi pelanggan dan pesaing. karena dua variabel ini mempunyai indikator yang berbeda. Orientasi pelanggan mempunyai indikator komitmen memuaskan pelanggan, mengumpulkan informasi kebutuhan pelanggan, cara memuaskan pelanggan, keluhan pelanggan, perhatian kepada pelanggan (Mavondo et al., 2005) dan orientasi pesaing mempunyai indikator diskusi informasi pesaing, informasi keunggulan pesaing, diskusi strategi pesaing, merespon tindakan pesaing, mengungguli pesaing (Mavondo et al., 2005). Dirincinya orientasi pasar ini bertujuan untuk dapat memberikan penjelasan variabel yang mempengaruhi orientasi inovasi dan kinerja pemasaran adalah variabel orientasi pelanggan atau orientasi pesaing sehingga penerapan pengembangan orientasi pasar akan lebih tepat. 
Variabel orientasi inovasi yang diteliti adalah variabel inovasi teknis karena UKM konveksi hanya melakukan inovasi teknik saja tidak melakukan inovasi administrasi.Variabel anteseden digunakan orientasi kewirausahaan bukan perilaku wirausaha karena lebih fokus, variabel reward berbasis pemasaran bukan reward intrinsic dan extrinsic karena dikaitkan dengan aktivitas pemasaran. Penelitian orientasi strategi untuk skala industri besar dilakukan oleh (Zhou, 2005; Rocelis, 2005; Eric, 2008; Ming \& Mei, 2010; Usta, 2011). Sedangkan untuk industri menengah dan kecil dilakukan oleh (Antonio, 2005; Grinstain, 2008; Nadrol, 2010). Penelitian ini semuanya dilakukan pada usaha industri. Usaha industri yaitu usaha konveksi pada dasarnya merupakan industi yaitu merubah bahan baku menjadi pakaian yang dijual pada pelanggan. Berdasakan uraikan ini maka penelitian cocok untuk UKM konveksi.

\section{Kinerja Pemasaran}

Kinerja pemasaran merupakan bagian dari kinerja organisasi. Kinerja organisasi terdiri atas kinerja pemasaran, kinerja keuangan, dan kinerja sumber daya manusia. Strategi perusahaan selalu diarahkan untuk menghasilkan kinerja pemasaran yaitu Volume penjualan, Market share, dan pertumbuhan penjualan dan kinerja pemasaran sebagai usaha pengukuran tingkat kinerja meliputi omzet penjualan, jumlah pembeli, keuntungan dan pertumbuhan penjualan (Voss \& Voss, 2000; Ferdinand, 2006).

\section{Orientasi Inovasi}

Orientasi inovasi adalah kegiatan menantang dan menghadapi ketidakpastian yang ada dan versi yang diperbaruhi orientasi inovasi merupakan pengembangan produk saat ini dan proses produksi, serta inovasi radikal yang pada dasarnya pengembangan atau penerapan ideide baru dan teknologi baru (Dewar dan Dutton, 1986).

\section{Orientasi Kewirausahaan}

Pengertian kewirausahaan dinyatakan oleh beberapa peneliti antara lain Wiklund (2003) dalam penelitiannya menyatakan kewirausahaan adalah proses strategi pembuatan kebijakan yang memungkinkan pengusaha untuk bertindak dan menjalankan organisasi sesuai dengan yang direncanakan dan mengacu pada hal-hal yang baru. Kewirausahaan cenderung meningkatkan yang baru, pengembangan produk lama, memfasilitasi penciptaan bisnis baru dan rekayasa operasi yang ada

\section{Orientasi Pelanggan}

Orientasi pelanggan adalah merupakan dimensi dari orientasi pasar yang paling utama. Mavondo, et al., (2005) dalam penelitiannya menjelaskan untuk meningkatkan orientasi pelanggan dengan cara meningkatkan indikator dari orientasi pelanggan. Indikator orientasi pelanggan yaitu: a) Komitmen dari semua pengelola terhadap usaha untuk memuaskan pelanggan. b) Mungumpulkan informasi kebutuhan dan keinginan pelanggan untuk dapat dipenuhi perusahaan. c) Berusaha menentukan cara memuaskan pelanggan. d) Berusaha untuk mengetahui keluhan pelanggan dan mencari penyebabnya serta berusaha untuk memperbaiki yang menyebabkan mengeluhnya pelanggan. e) Berusaha selalu memberikan perhatian khusus kepada setiap pelanggan.

\section{Orientasi Pembalajaran}

Orientasi pembelajaran merupakan faktor penting dalam memperoleh keunggulan kompetitif (Brockman \& Morgan, 2003). Orientasi pembelajar dikenal sebagai penerimaan pembelajaran dalam organisasi (Nee, Park dan Lee, 2009). 


\section{METODE PENELITIAN}

Unit analisis dari penelitian ini adalah UKM konveksi. UKM konveksi ini merupakan organisasi.

Populasi penelitian ini adalah pemilik atau pengelola UKM konveksi di Kabupaten Sragen. Kriteria pemilik atau pengelola UKM yang dijadikan populasi dalam penelitian ini adalah data yang publikasikan oleh BPS sebagai UKM dan sesuai dengan (UU. No. 20 tahun 2008) Kriteria ini yaitu:

1. Memiliki tenaga kerja 5-19 orang untuk usaha kecil dan 20-99 orang untuk usaha menengah.

2. Memiliki asset 50 juta-500 juta rupiah untuk usaha kecil dan lebih 500 juta - 5 milyard rupiah untuk usaha menengah.

3. Memiliki omzet penjualan tahunan 300 juta 2.5 miyard rupiah untuk usaha kecil dan lebih dari 2.5 milyar - 50 milyar rupiah untuk usaha menengah.

4. Tidak merupakan cabang dari perusahaan besar. Usaha mikro tidak diikutkan dalam penelitian ini karena sebagian besar tidak bersedia dijadikan responden.

5. Jumlah pemilik atau pengelola UKM konveksi di Kabupaten Sragen yang menjadi populasi adalah 970 orang (disperindag Kabupaten Sragen, 2015)

Sampel dalam penelitian ini adalah sebesar $970 \times 10 \%=97$ responden, dibulatkan menjadi 100 responden, maka dalam penelitian ini sampelnya 100 responden UKM konveksi di Kabupaten Sragen.

Teknik analisis dalam penelitian ini menggunakan analisis jalur (path anlysis) yang menghubungkan antara pengaruh langsung dan tidak langsung.

\section{HASIL PENELITIAN DAN PEMBAHASAN}

\section{Analisis Jalur}

Dalam penelitian ini analisis jalur ini digunakan untuk mengetahui pengaruh dari variabel bebas terhadap variabel terikat dengan menggunakan tiga persamaan
Tabel 1.

Hasil Analisis Jalur Persamaan 1

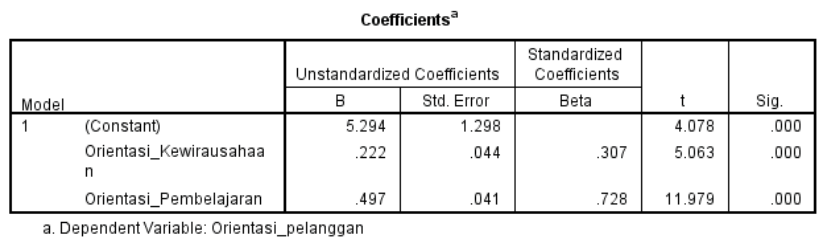

$\mathrm{Y}_{1}=0,307 \mathrm{X}_{1}+0,728 \mathrm{X}_{2}+\epsilon_{1}$

Dari hasil analisi menunjukkan bahwa orientasi kewirausahaan dan orientasi pembelajaran berpengaruh positif terhadap orientasi pelanggan di UKM konveksi Kabupaten Sragen.

Tabel 2.

Hasil Analisis Jalur Persamaan 2

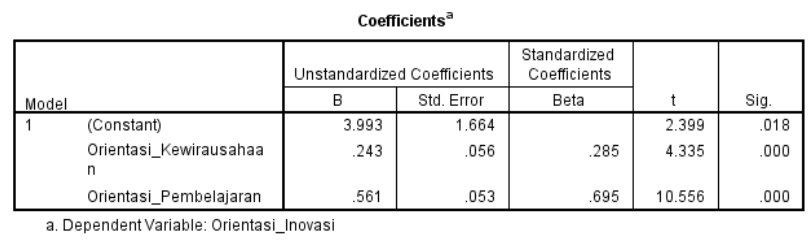

$\mathrm{Y}_{2}=0,285 \mathrm{X}_{1}+0,695 \mathrm{X}_{2}+\epsilon_{2}$

Dari hasil analisi menunjukkan bahwa orientasi kewirausahaan dan orientasi pembelajaran berpengaruh positif terhadap orientasi inovasi di UKM konveksi Kabupaten Sragen.

Tabel 3. Hasil Analisis Jalur Persamaan 3

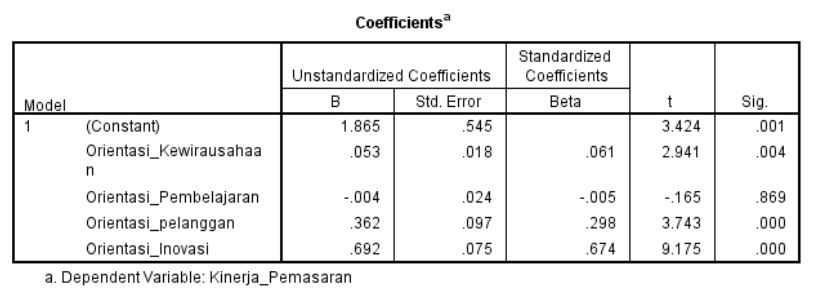
$Y_{3}=0,061 X_{1}-0,005 X_{2}+0,298 X_{3}+0,674 X_{4}+\epsilon_{3}$

Dari hasil analisi menunjukkan bahwa orientasi kewirausahaan, orientasi pelanggan dan orientasi inovasi berpengaruh positif 
terhadap kinerja pemasaran, sedangkan orientasi pembelajaran berpengaruh negatif terhadap kinerja pemasaran di UKM konveksi Kabupaten Sragen.

\section{Hasil Uji t}

1. Dari Uji t pada persamaan Pertama dapat disimpulkan bahwa Variabel Orientasi kewirausahaan dan Orientasi pembelajaran berpengaruh positif dan signifikan terhadap Orientasi pelanggan. Hal ini dapat dilihat dari nilai signifikansi masing-masing variabel < 0,05 .

2. Dari Uji t pada persamaan kedua dapat disimpulkan bahwa Variabel Orientasi kewirausahaan dan orientasi pembelajaran berpengaruh positif dan signifikan terhadap Orientasi inovasi . Hal ini dapat dilihat dari nilai signifikansi masing-masing variabel < 0,05 .

3. Dari Uji t pada persamaan Ketiga dapat disimpulkan bahwa variabel Orientasi kewirausahaan, Orientasi pelanggan dan Orientasi inovasi berpengaruh positif dan signifikan terhadap Kinerja pemasaran. Hal ini dapat dilihat dari nilai signifikansi masingmasing variabel $<0,05$. Dan Orientasi pembelajaran berpengaruh negatif dan tidak signifikan terhadap Kinerja pemasaran.

\section{Hasil Uji F}

Hasil uji secara serempak (Uji F) pada persamaan ketiga diketahui besarnya nilai $\mathrm{F}=$ 715,677 signifikansi $0,000<0,05$. Sehingga dapat disimpulkan secara bersama-sama variabel bebas mempengaruhi Kinerja pemasaran.

\section{Koefisien Determinasi Total}

Nilai $\mathrm{R}^{2}$ total sebesar 0,856 dapat diartikan variasi Kinerja pemasaran di UKM konveksi Kabupaten Sragen dijelaskan oleh variabel orientasi kewirausahaan, orientasi pembelajaran, orientasi pelanggan, orientasi inovasi dan sebesar $85,6 \%$ dan sisanya $14,4 \%$ dijelaskan variabel lain diluar model penelitian.

\section{Tabel 4. Pengaruh Langsung, Pengaruh Tidak Langsung dan Total Pengaruh}

\begin{tabular}{|c|c|c|c|}
\hline \multirow[b]{2}{*}{ Dari Variabel } & \multicolumn{2}{|c|}{ Koefisien Jalur } & \multirow[b]{2}{*}{ Total Pengaruh } \\
\hline & $\begin{array}{c}\text { DE } \\
\text { (Direct } \\
\text { Effect }) \\
\end{array}$ & $\begin{array}{c}\mathrm{IE} \\
\text { (Indirect Effect) }\end{array}$ & \\
\hline $\mathrm{X}_{1}$ ke $\mathrm{Y}$ & $P_{5}=0,061$ & & \\
\hline $\mathrm{X}_{2}$ ke Y & $P_{0}=-0,005$ & & \\
\hline $\mathrm{X}_{1}$ melalui $\mathrm{X}_{3} \mathrm{Ke} \mathrm{Y}$ & & $\begin{array}{c}P_{1} \times P_{7}= \\
0,307 \times 0,298 \\
=0,091\end{array}$ & $\begin{array}{c}\mathrm{P}_{5}+\left(\mathrm{P}_{1} \mathrm{xP}_{7}\right)= \\
0,061+0,091 \\
=0,152\end{array}$ \\
\hline $\mathrm{X}_{2}$ melalui $\mathrm{X}_{3} \mathrm{Ke} \mathrm{Y}$ & & $\begin{array}{c}\mathrm{P}_{2} \times \mathrm{P}_{7}= \\
0,728 \times 0,298 \\
=0,216\end{array}$ & $\begin{array}{c}\mathrm{P}_{6}+\left(\mathrm{P}_{2} \mathrm{XP}_{7}\right)= \\
-0,005+0,216 \\
=0,211\end{array}$ \\
\hline $\mathrm{X}_{1}$ melalui $\mathrm{X}_{4} \mathrm{Ke} \mathrm{Y}$ & & $\begin{array}{c}P_{3} \times P_{8}= \\
0,285 \times 0,674 \\
=0,192\end{array}$ & $\begin{array}{c}\mathrm{P}_{5}+\left(\mathrm{P}_{3} \times \mathrm{P}_{8}\right)= \\
0,061+0,192 \\
=0,253\end{array}$ \\
\hline $\mathrm{X}_{2}$ melalui $\mathrm{X}_{4} \mathrm{Ke} \mathrm{Y}$ & & $\begin{array}{c}\mathrm{P}_{4} \times \mathrm{P}_{8}= \\
0,695 \times 0,674 \\
=0,468\end{array}$ & $\begin{array}{c}\mathrm{P}_{6}+\left(\mathrm{P}_{4} \times \mathrm{P}_{8}\right)= \\
-0,005+0,468 \\
=0,463\end{array}$ \\
\hline
\end{tabular}

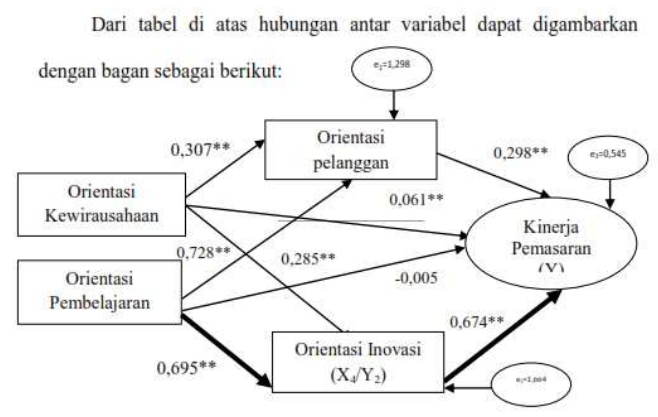

Dari gambar pengaruh langsung dan tidak langsung tersebut dapat diambil kesimpulan bahwa variabel yang paling dominan adalah variabel orientasi pembelajaran melalui orientasi inovasi terhadap kinerja pemasaran.

\section{KESIMPULAN DAN SARAN}

\section{Kesimpulan}

Dari hasil analisis jalur yang paling efektif adalah orientasi pembelajaran melalui orientasi inovasi karena memiliki nilai yang paling tinggi yaitu sebesar 0,468 .

\section{Saran}

1. Orientasi pelanggan perlu ditingkatkan lagi karena mempunyai pengaruh yang signifikan terhadap kinerja pemasaran yaitu dapat dilakukan dengan cara Karyawan UKM konveksi Kabupaten Sragen memiliki 
komitmen yang kuat untuk memuaskan pelanggan, UKM konveksi Kabupaten Sragen melaksanakan pelayanan cara memuaskan konsumen dan UKM konveksi Kabupaten Sragen selalu melaksanakan kebutuhan dan keinginan pelanggan.

2. Orientasi inovasi perlu ditingkatkan kembali, hal ini dapat dilakukan dengan cara UKM konveksi Kabupaten Sragen memberikan cara terbaru untuk meningkatkan mutu konveksi, UKM konveksi Kabupaten Sragen melaksanakan sering perkenalkan proses produksi baru dan UKM konveksi Kabupaten Sragen selalu selalu perkenalkan pelayanan baru

\section{DAFTAR PUSTAKA}

Alessio, T. Elisa, P., Cipriano, F. (2012). Product Configurator Impact on Product Quality, International Journal of Production Economics, Vol. 135. p. 850-859.

Altindag, E. Zehir, C. \& Acar, A.Z. (2010). Strategic Orientations and Their Effects on Firm Performance in Turkish Family Owned Firms, Journal Eurasian Business Review, Vol. 1. p. 18-36.

Ambler, T. \& Puntoni, S. (2003), Measuring Marketing Performance. In Hart, $S$ (Ed.), Marketing Changes, London, UK: Thomson Learning, p. 289-309.

Ana, L. Dionysis, S. \& Carmen, L. (2011). Innovative Capabilities: Their Drivers and Effects on Current and Future Performance, Journal of Business Research. Vol.64, p. 34-48.

Andreas, K. \& Marcus, W. (2010). The Influence of Sustainability Orientation on Entrepreneurial Intentions Investigating the Role of Business Experience, Journal of Business Venturing, Vol. 25, p. 524-539.
Andrew, S. (2010). The Paradox of MarketOriented Public Policy and Poor Productivity Growth in Canada, Published in A Festschrift in Honour of David Dodge's Contributions to Canadian Public Policy, Bank of Canada Antonio, N.F. Emilio, R, \& Jose, D. (2005). Implication of Perceived Competitive Advantage, Adaptation of Marketing Tactics and Export Commitment on Export Performance, Journal of World Business, Vol. 45. p. 287-300

Asikhia, U. ( 2009 ). The Moderating Role of E - Marketing on the Consequences of Market Orientation in Nigerian Firms, Department of Business Studies College of Business and Social Sciences Covenant University.

Baker, W.E. \& Sinkula, J.M. (2009). The complementary effects of market orientation and entrepreneurial orientation on profitability in small businesses, Journal of Small Business Management, Vol. 47. p. 443-464

Banterle, A, Cavaliere.A, Stranieri .S \& Laura C.( 2009), The Relationship B e twe en Innovation and Marketing in SMEs in the EU, Food Sector1 Department of Agricultural, Food and Environmental Economics, Università degli Studi di Milano, Italy.

Basile, A. (2012). Entrepreneurial Orientation in Smes: Risk-Taking To Entering International Markets, Journal Far East Journal of Psychology and Business, Vol. 7. p. 87-103

Beal, T \& Abdullah, MA. (2003). The Strategic Contributions Of Small And Medium Enterprises To The Economics Of Japan And Malaysia, Some Competitive Lessons For Malaysian SMEs, Paper Presented to The Seventh Iternational 
Conference Global Business and Economic Development Strategic For Sustainable Bisiness Responses to Regional Demand, and Global Opportunity, Bangkok Thailand. p. 5669

Beatrix, L, (2008), Innovation As The Key of The Pharmaceutical Companiesa Competitive Advantage, Journal on Agricultural Economics, Vol. 51.p. 145170

Bilal, Y, (2010). A General Conceptual View on Resource Advantage Theory, Journal Business and Economics Research Journal, Vol.1. p. 63-79

Boer, H., \& During, W. E. (2001). Innovation, what innovation? A comparison between product, process, and organizational innovation, International Journal of Technology Management, Vol.22. p. 83-107.

Buono, A.F. \& Kerber, K.W. (2008). The Challenge of Organizational Change: Enhancing Organizational Change Capacity, Revue Sciences de Gestion, Vol. 65. p. 99-118.

Calantone, S.T., Cavusgil \& Zhao Y., , 2002 Learning orientation, firm innovation capability, and firm performance, Industrial Marketing Management, Vol.3. p. $515-524$

Camelia C. (2012).The Impact Of Latest It Technologies Over The Efficiency Of A Knowledge-Based Organization Management In Romania, Revista economica, Vol. Supplement p. 68-76

Carpenter, H., (2010), Definition of innovation, WWW/ Claudion /202/definition of innovation, 29 Juni 2010

Cristina, S. (2011). The Marketing Entrepreneurship and The SMEs Competitiveness, Journal of Knowledge
Management, Economics and Information Technology, Vol. 1. p. 8-25. Cucculelli M. (2012).New Product Introduction And Product Tenure: What Effects On Firm Growth?,journal Research Policy, Vol. 41. p. 808-821

Darroch, J. (2005). Knowledge Management, Innovation and Firms Performance, Journal of Knowledge Management, Vol. 9, p. 101-115

Dentoni \& Domenico (2011), R\&D Projects Fostering Small Firms' Market-Sensing and Customer-Linking Capabilities: A Multivariate Statistics Approach Australian Agricultural and Resource Economics Society, Conference (55th), February 8-11, Melbourne, Australia.

Devlin, S. Kudenko, D. \& Grzes, M. (2011). An Empirical Study of PotentialBased Reward Shaping and Advice in Complex, Multi-Agent Systems, Artile Provided by World Scientific Publishing Co. Pte. Ltd. its Journal, Vol.14. p. 251278.

Dewar, R.D. Dutton, J.E. (1986). The Adoption Of Radical And Incremental Innovations: An Empirical Analysis, In: Management Science, Vol. 32, p. 1422-1433.

Ellen, G. (2011), Analysis of Value-Added Meat Product Choice Behaviour by Canadian Households University of Alberta, Department of Resource Economics and Environmental Sociology in its series Project Report Series with number 99703.

Eric, T. M, \& R. Hamish, G. (2008). Market Orientation, Innovation and Entrepreneurship: An Empirical Examination of the Illinois Beef Industry, Journal International Food and Agribusiness Management Review, Vol. 11. p. 232-281 
Eris, E.D \& Ozmen, O.N.T. (2012), The Effect of Market Orientation, Learning Orientation and Innovativeness on Firm Performance: A Research From Turkish Logistics Sector Technological Educational Institute Of Kavala, International Journal of Economic Sciences and Applied Research (IJESAR), Vol. 5. p. 77-108

Ferdinand, A. (2006). Strategic Pathways Toward Sustainable Competitive Advantage. Unpublished DBA, Theses.Soutern Cross. Lismore. Australia.

Foltean, F, (2007), The Entrepreneurial Approach in Marketing, Journal Management \& Marketing, Vol. 2. p. 46-58

Fosfuri, A, \& Tribo, J.A, (2008), Exploring the Antecedents of Potential Absorptive Capacity and Its Impact on Innovation Performance, Journal Omega, Vol. 36. p. 173-187.

Francesco, B, \& Mario, P, (2011). Engines of Growth. Innovation and Productivity in Industry Groups, Journal Structural Change and Economic Dynamics, Vol. 22. p. $27-69$

Garvin, D.A. (2000). Learning In Action: A GuiDe To Putting The Learning Organization To Work, Boston: Harvard Business School Press,

Garcia, R. Calantone, R. (2002). A Critical Look At Technological Innovation Typology And Innovativeness Terminology: A Literature Review, In: Journal of Product Innovation Management, Vol. 19. p. $110-132$

Gheorghe, P, \& Alexandru, S.C. (2010). Innovation Performance Factor of Economic Entities, Journal Annals of Computational Economics, Vol. 3. p. 12-25.

Ghozali, I. (2008). Model Perencanaan Structural Konsep \& Aplikasi Dengan Program
Amos 16 .0, Badan Penerbit UNDIP, Semarang

Grawe.S.J, (2009), The Relationship Between Strategic Orientation, Service Innovation, And Performance, Emerald Group Publishing Limited

Grinstein, A. (2008). The Effect Of Market Orientation and Its Components on Innovation Consequences: A MetaAnalysis, Journal of Academy of Marketing Science, Vol. 36. p. 166-73

Gurhan, G, Gunduz, U, Kemal, K, \& Lutfihak, A, (2011). Effects of Innovation Types on Firm Performance, Journal of Production Economics, Vol. 133 p. 662-676.

Hansen, E., S. Korhonen, E. Rametsteiner, and S. Shook. (2006). Current state-ofknowledge: Innovation research in the global forest sector, Journal of Forest Products Business Research, Vol. 3. p. 27-43.

Hovgaard, A., \& E. Hansen. (2004). Innovativeness In The Forest Products Industry, Forest Products Journal, Vol. 54. p. 26-33.

Hultén, Peter (2012)A Lindblomian perspective on customer complaint management policies, Journal of Business Research, Vol. 65. p. 788-793

Hurley, Robert F. and Hult, Thomas M. (1998). Innovation, Market Orientation, an Organizational Learning: An Integration and Empirical Examination, Journal Marketing, Vol. 62. p. 42-54.

Imoleayo, F. O., (2010). The Impact of Product Price Changes on the Turnover of Small and Medium Enterprises in Nigeria, Journal brand Broad Research in Accounting, Negotiation, and Distribution, Vol. 1. p. 60-79

Ionica, D., (2010). Innovation-A Way of Increasing Small and Medium-Sized 
Tourism Enterprises Competitiveness, Journal Romanian Economic and Business Review, Vol. 5. p. 156-161.

Jhon, B. (2009). Organizational Emotional Capability, Product and Process Innovation, and Firm Performance: An Empirical Analysis, Journal Of Engineering and Technology Management Archive, Vol. 6. p. 45-56.

Jhonson, A.J. Dibrell, C.C. \& Eric, H. (2009). Market Orientation, Innovativeness, and Performance of Food Companies, Journal of Agribusiness, Vol. 27. p. 85106

Jumaev， M. Kumar， D. \& M. Hanaysha (2012) Impact Of Relationship Marketing On Customer Loyalty In The Banking Sector, Journal Far East Journal of Psychology and Business, Vol. 6. p. 3655

Kandemir \& G.T.M., Hult, (2005) a Conceptualization of an Organizational Learning Culture in International joint Ventures, Industrial Marketing Management, Vol. 34. p. 430-439.

Kanchanda, K. (2011) Organizational Flexibility Capability, Inovation Advantage and Firm Sustainability: Evidence From Electronic Manufacturing Businesses in Thailand: International Journal of Business Strategy, ISSN: 1553-9563

Kaya, N. \& Patton, J, (2011). The Effects of Knowledge-Based Reseources, Market Orientatation and Learning Ori entation on Innovation Performance: An Empirical Study of Turkish Firms, Journal of International Development, Vol. 23. p. 204-219.

Kirca, A, H., Jayachandran, S. and Bearden, W. O (2005). Market Orientation: A MetaAnalityc Review and Assessment of Its Antecedents and Impact on Performance, Journal of Marketing, Vol. 69. p. 24-4.
Kotler, P. (2010). Marketing Management Analysis, Planning, Implementation, and Control, $12^{\text {th }}$ Ed. Englewood Cliff, NJ. New Jersey: Prentice-Hall, Inc.

Lewrick 1, M., M. Omar2 \& Robert L.W. $\mathrm{Jr}$, (2011). Market Orientation and Innovators' Success: an Exploration of the Influence of Customer and Competitor Orientation Technol, Journal Management Innovasion, Vol. 6. p. 48-62

Liau, T.S, \& Rice, J. (2010). Innovation Investments, Market engagement and Financial Performance: A Study Among Australian Manufacturing SMEs, Article Provided by Elsevier in its Journal Research Policy, Vol. 39. p.117-125.

Lin, C.H, Peng, C.H, \& Kao, D.T (2008). They are Innovative Tiveness Effect of Market Orientatation and Learning Orientation is a Business Performance, Journal of Manpower, Vol. 29. p. 752-772.

Lin F.R. \& Hsieh P.S. (2011). A SAT View on New Service Development, Service Science, Vol. 3. p. 141-157

Lukas, B.A \& O.C Ferrell (2000). The Effect of Market Orientation on Product Innovation, Journal of Academy of Marketing Science, Vol. 28. p. 239-247.

Lumkin, G.T. \& Ferrel (1996). Clarifying The Entrepreneurial Orientation Construct and Linking It Performance, Academy of Management Review, Vol. 21. p. 135172.

Ma'atoofi, A.R. \& K.Tajeddini. (2010). The Effect of Entrepreneurship Orientation on Learning Orientation and Innovation: A Study of Small-Sized Business Firms in Iran, International Journal of Trade, Economics and Finance, Vol. 1. p. 254260 
Matsuno, K. \& Metzer, J.T. (2000). The Effects of Strategy Type on The Market Performance Relationship, Journal of Marketing Vol. 64. p. 1-16.

Mavondo, Felix, T. Chimhanzi, Jacqueline, Stewart \& Jillian. (2003). Learning Orientation and Market Orientation : Relationship With Invitation, Human Resource Practices and Performance, European Journal of Marketing, Vol. 39, p. 1235-1263.

Merriam \& Caffarella, (1991), Four Fundamental Orientations (Perspectives) for Learning Theories http: //www.lifecirclesinc. $\mathrm{com} /$ Learningtheories / orientations. html

Micheels, Eric T. \& Gow, H.R. (2009). Do Market Oriented Firms Demonstrate Clarity on Their Value Discipline? Evidence from Illinois Beef Producers Article provided by International Food and Agribusiness Management Association (IAMA), Journal International Food and Agribusiness Management Review, Vol. 12. p. $34-45$

Milfelner, B, \& Snoj, B, (2008), Can Innovation Resources Influence Company Performance : Caseof Slovenia, Journal of sustaninable Economy, Vol. 1, p. 6069.

Miller, J. (2003). Outsourcing is Front Page. Canadian Journal of Administrative Science. Vol. 27. p. 168-179.

Ming, L.C. (2011), Team and Organizational Resources, Strategic Orientations, and Firm Performance in a Transitional Economy, Journal of Business Research, Vol. 64, p. 1344-1351.

Ming, T.T. \& Mei, S.C. (2010). The Impact of Marketing Knowledge Among Managers on Marketing Capabilities and Business Performance, International Journal of Management, Vol. 21. p. 524-530.
Morgan, R.E, \& Berthon, P (2008). Market Orientation, Generative Learning, Innovation Strategy and Business Performance Inter-Relationships in Bioscience Firms, Journal of Management Studies, Vol. 45. p. 20-38

Morgan, N.A., D.W. Vorhies \& Charlotte H. M. (2009). Market orientation, marketing capabilities, and firm performance, Strategic Management Journal, Vol. 30. p. 909 - 920.

Morris, M.H. Coombes, S. \& Schindehutte, M. (2007). Antecedent And Outcomes of Entrepreneurial and Market Orientation In Anon- Profit Context: Theoretical And Empirical Insights, Journal of Leadership and Organization Studies, Vol.13. p. 12-39.

Nadrol, W,M. Breen, J.\& Josiassen, A. (2010). Relationship Between Strategic Orientation And SME Firm Performance: Developing A Conceptual Framework, Contact: Breen, J.Victoria University Melboune, Australiap, Vol. 8. p. $713-723$

Narver, J.C. \& Slater, S.F. (2004). The Effect of A Market Orientation on Business Profitability, Journal of Marketing Research, Vol. 54. p. 20-35.

Nawawi, A.W. (2009). Peran UKM Pada Perekonomian Nasional Ditengah Ancaman Krisis Global, WWW. Atmplaza@.com

Nguyen and Nigel J., Barrett, (2006). The Adoption of the Internet by Export Firms in Transitional Markets, Asia Pacific Journal of Marketing and Logistics. Vol. 18. p. 29-42.

Nybakk, E. (2012). Learning Orientation, Innovativeness And Financial Performance In Traditional Manufacturing Firms: A Higher-Order 
Structural Equation Model, International Journal Of Innovation Management, Vol. 16. p. 1250029-1-1250029-28

Olsson, A. (2007). Transformation To A Customer-Oriented Perspective Through Action Learning In Product And Service Development, Journal action learning research and practice, Vol. 4. p. 45-59

Omar, M., Nwanko, S. \& Richards, D, (2008), Determinants of International Entrepreneurship of UK Companies, Journal World Review of Entrepreneurship, Management and Sustainable Development. Vol. 4, p. $1-18$.

Pau, A. (2011). The Role of The Orientation TowardsInnovation WithinOrganisation, Journal Annals of Computational Economics, Vol. $2 . \quad$ p. 151-155.

Rhee, J., Park, T., \& Lee, D. H. (2010). Drivers of innovativeness and performance for innovative SMEs in South Korea: Mediation of Learning Orientation Technovation, Vol. 30. p. 65-75.

Rocelis, A.D. (2005). Relationship Between Strategic Orientation and Organizational Performance : An Exploratory Study of Philiphippine Companies, Philippine Management Review, Vol. 13. p. 70-80

Rock, A, \& Agca V. (2009). Entrepreneurial Orientation and Performance of Turkish Manufacturing FDI Firms: An Empirical Study, Journal Economics Business and Finance, Vol. 24. p. 115-133.

Rogers, E. M. (2003). Diffusion of Innovations, 5th edition. New York: Free Press $\mathrm{p}$. 424-438.

Ruokonen, M., \& Saarenketo, S. (2009). The Strategic Orientations of Rapidly Internationalizing Software Companies, European Business Review, Vol. 21. p. $17-41$.
Schildt, Hendri, A., Maula, Markku, V.J. and Keil, T., (2005). Exploitative Learning from External Corporate External Corporate Venture, Entrepreneurship Theory and Practice. Vol. 29. p. 493-515.

Schindehutte, M., Morris, M. H., \& Kocak, A. (2008). Understanding Market Driving Behaviour: The Role of Entrepreneurship, Journal of Small Business Management, Vol. 46. p. 4-26.

Schroeder R.G., Bates K.A., Juntila M.A. (2002). A Resource-Based View of Manufacturing Performance, Strategic Management Journal, Vol. $23 . \quad$ p. 105-117.

Sekaran, U., Roger, B. (2010). Research Methods For Business ASkill Building Approarch, A John Wiley and Sons Ltd publication Fith Edition

Sergio, O. \& Roberto, F. (2008). Market orientation, knowledge related resources and firm performance, Journal of research business, Vol. 61. p. 623-630

Shabbir, S. Ahmed, K. Kaufmann, H.R. \& Malik, E. (2010). Entrepreneur Proactiveness and Customer Value: the Moderating Role of Innovation and Market Orientation, Journal World Review of Entrepreneurship, Management and Sustainable Development, Vol. 6. p. 189-205.

Silkoset. (2009). Market Orientation Capabilities: A Study of Learning Processes in Market-oriented Companies, Published at VDM-Verlag, ISBN: 978-3-63904429-4.

Silkoset. \& Ragnhild. (2009). Co-market Orientation in Networks. Published at VDM-Verlag, ISBN: $\quad$ 978-3-63904429-4. 
Soca, D. (2011). Relationship Marketing-The Key of The Success In Business, Journal Romanian Economic and Business Review, Vol. 6. p. 177-183.

Stare, A. (2012). The Impact of a Project Organisational Culture and Team Rewarding on Project Performance, Article Provided by Rainer Hampp Verlag in its Journal, Vol.17. p. 40-67.

Stein, J.C. (2008). Growth versus Margins: Destabilizing Consequences of Giving the Stock Market What It Wants, American Finance Association in The Journal of Finance. Vol. 63. p. 10251058

Stephen J. N., Bob T. W., Philip A., Titus, S. \& M. Petroshius, (2012). The role of shopping sophistication in creating satisfying purchase outcomes, Emerald Group Publishing, Journal American of Business Vol. 26. p. 129-144

Sylvie, L. (2008). Size, Strategic, and Market Orientation Affects on Innovation, Elsevier in Journal, Vol. 61. p. 753-764.

Tang, Z, Tang, J, Marino, L.D., Zhang, Y, \& Li, Q, (2010). An Investigation of Entrepreneurial Orientation and Organisational Strategies in Chinese SMEs, Journal World Review of Entrepreneurship, Management and Sustainable Development. Vol. 6. p. 206-223.

Urata, S. (2000). Policy Recommendation for SME Promotion In The Republic of Indonesia, JICA Senior Advisor to Coordination Minister of Economy, Finance and Industry. Jakarta.

Usta, R. (2011). Strategic Orientations Enriching the Effect of Market Orientation on Company Performance: Literature-
Based Holistic Model Proposal, Journal Anadolu University Journal of Social Sciences, Vol.11. p. 34-45

Verhess, F. \& Meulenberg M.T.G. (2004) Market Orientation, Innovativeness, Product Innovation, and Performance In Small Firms. Journal of Small Business Management, Vol. 42. p. 134-154.

Voss, G.B., \& Voss Z.G. (2000). Strategic Orientation and Firm Performance In an Artistic Enviroment, Journal of Marketing, Vol. 64. p. 67-83.

Wales, R. (2009). Digestion During Continuous Culture Fermentation When Replacing Perennial Ryegrass With Barley and Steam-Flaked Corn Journal of Dairy Science, Vol. 92. p. 189-197

Wang, C.L (2008). Entrepreneurial Orientation, Learning Orientation, and Firm Performance, Entrepreneurship Theory \& Practice, Vol. 32. p. 635-657

Wencong Ma., Guilong. Z. \& Yu, H. (2011). Learning Orientation, Process Innovation, and Firm Performance in Manufacturing Industry School of Business Administration, South China University of Technology, Guangzhou, China, Advances information science and sevice science vol. 3. p.1-4

Wiklund, J., Lumpkin, G.T.T. \& Frese, M. (2009). Entrepreneurial orientation and business performance: An assessment of past research and suggestions for the future, Entrepreneurship Theory and Practice, Vol. 33. p. 761-787.

Xinming, H. \& Yingqi, W. (2011). Linking Market Orientation To International Market Selection And International Performance, Journal International Business Review Vol. 20. p. 535-546 
Yichen, L. Yichuan, W. \& Chiahui, Y. (2010). Investigating the Drivers of the Innovation in Channel Integration and Supply Chain Performance: A Strategy Orientated Perspective, Journal of Production Economics, Vol. 127 p. 246276

Zahra, S.A., Ireland, R.D. \& Hutt, M.A. (2000). International Expansion by New Venture Firm: International Diversity, Mode of Market Entry, Technological Learning, and Performance, Academy of Management Journal, Vol. 43. p. 925950.
Zhi T. \& Jintong T., (2012). Stakeholder-firm power difference, stakeholders' CSR orientation, and SMEs' environmental performance in China. Journal of Business Venturing, Vol. 27. p. 436-455

Zhou, K.Z. Yim, C.K. \& Tse, D.K. (2005). The Effects of Strategic Orientationson Technology and Market Based Breakthrough Innovations, Journal of Marketing, Vol. 69. p. 40-60 